\title{
Effect of peracetic acid on biofilms formed by Staphylococcus aureus and Listeria monocytogenes isolated from dairy plants
}

\author{
S. H. I. Lee, ${ }^{*}$ L. P. Cappato, † C. H. Corassin, ${ }^{*}$ A. G. Cruz, $\ddagger$ and C. A. F. Oliveira* ${ }^{* 1}$ \\ *University of São Paulo, School of Animal Science and Food Engineering, Department of Food Engineering, Av. Duque de Caxias Norte, 225, \\ CEP 13635-900 Pirassununga, SP, Brazil \\ †Federal University Rural of Rio de Janeiro (UFRRJ), Food Technology Department, CEP 23890-000, Seropédica, RJ, Brazil \\ †Federal Institute of Rio de Janeiro (IFRJ), Food Department, CEP 20270-021, Rio de Janeiro, RJ, Brazil
}

\begin{abstract}
This research investigated the removal of adherent cells of 4 strains of Staphylococcus aureus and 1 Listeria monocytogenes strain (previously isolated from dairy plants) from polystyrene microtiter plates using peracetic acid (PAA, 0.5\%) for 15, 30, 60, and $120 \mathrm{~s}$, and the inactivation of biofilms formed by those strains on stainless steel coupons using the same treatment times. In the microtiter plates, PAA removed all $S$. aureus at $15 \mathrm{~s}$ compared with control (no PAA treatment). However, L. monocytogenes biofilm was not affected by any PAA treatment. On the stainless steel surface, epifluorescence microscopy using LIVE/DEAD staining (BacLight, Molecular Probes/Thermo Fisher Scientific, Eugene, OR) showed that all strains were damaged within 15 s, with almost $100 \%$ of cells inactivated after $30 \mathrm{~s}$. Results of this trial indicate that, although PAA was able to inactivate both $S$. aureus and $L$. monocytogenes monospecies biofilms on stainless steel, it was only able to remove adherent cells of $S$. aureus from polystyrene microplates. The correct use of PAA is critical for eliminating biofilms formed by $S$. aureus strains found in dairy plants, although further studies are necessary to determine the optimal PAA treatment for removing biofilms of L. monocytogenes.
\end{abstract}

Key words: Staphylococcus aureus, Listeria monocytogenes, biofilm, peracetic acid

\section{INTRODUCTION}

In natural and manufactured ecosystems, bacteria cells have a tendency to live attached to surfaces and to form a complex structure called a biofilm (Abdallah et al., 2014). Once biofilms are formed on a contact surface, they become quite resistant to antimicrobial

Received June 24, 2015.

Accepted November 6, 2015.

${ }^{1}$ Corresponding author: carlosaf@usp.br agents because of the slimy layer formed by bacteria (Martins and Germano, 2011). The persistence of biofilm on food contact surfaces and equipment may constitute a continuous source of contamination (Abdallah et al., 2014). Moreover, several reports have already shown the ability of bacteria species to produce biofilms on materials commonly used in the food industry, such as stainless steel, glass, rubber, and polystyrene (Simões et al., 2010). Bacterial cells in biofilms are considered difficult or even impossible to eradicate (Cos et al., 2010; Römling and Balsalobre, 2012). Additionally, biofilm formation on dairy equipment can lead to economic loss due the deterioration of food and equipment (Bremer et al., 2006).

Pathogenic microorganisms including Listeria monocytogenes and Staphylococcus aureus are of great concern in the food processing industry (Cappitelli et al., 2014) and have demonstrated high capacity to produce biofilms on surfaces, especially in the environment of dairy plants (Sasidharan et al., 2011). In the food processing industry, the development of biofilm will depend on the frequency of sanitation regimens (Cappitelli et al., 2014). Usually, the efficacy of disinfectants against biofilms increases with increasing biocide concentration and time of treatment (Surdeau et al., 2006; Belessi et al., 2011). However, the resistance of pathogens to sanitizers widely used in food industry can be one of the factors contributing to the involvement of specific microorganisms in foodborne outbreaks.

In dairy plants, one of most used sanitizers is peracetic acid (PAA), which has a wide spectrum of antimicrobial activity (Falsanisi et al., 2006) and is active at low temperatures $\left(0-25^{\circ} \mathrm{C}\right.$; Ölmez and Kretzschmar, 2009). Also, PAA decomposes into safe and environmental friendly residues (acetic acid and hydrogen peroxide), and its efficacy is not affected by protein residues, hence it can be applied without risk of contaminating food with toxic residues (Souza et al., 2014). However, little information exists on the effectiveness of PAA on biofilms formed by foodborne pathogens, except for the study of Marques et al. (2007), who found that PAA 
had higher efficiency in removing adhered cells of $S$. aureus compared with hydrogen peroxide and sodium dichloroisocyanurate. The aim of this study was to investigate the effect of PAA treatment for different times on removal and inactivation of monospecies biofilms formed on microtiter plate and stainless steel coupons by 4 strains of $S$. aureus and $1 \mathrm{~L}$. monocytogenes strain isolated from dairy plants, using a biofilm-forming index (BFI) according to Srey et al. (2014), and the visualization of biofilms by epifluorescence microscopy.

\section{MATERIALS AND METHODS}

\section{Bacterial Strains}

Four $S$. aureus strains (SA1, SA2, SA3, and SA4) and one L. monocytogenes $(\mathbf{L M})$ strain were used in the study. The LM strain was isolated from brine in a dairy plant located in São Paulo State, Brazil (Barancelli et al., 2011). Strains SA1 and SA2 were isolated from bulk tank milk in São Paulo State, Brazil, as described by Lee et al. (2012). Strains SA3 and SA4 strains were isolated from brine and glove swabs collected in dairy plants located in São Paulo State. After 10-fold dilution of samples, $0.1 \mathrm{~mL}$ of each dilution was surface plated on Baird Parker agar (Oxoid, Basingstoke, UK) supplemented with egg-yolk emulsion (Oxoid) and incubated at $37^{\circ} \mathrm{C}$ for 24 to $48 \mathrm{~h}$. Isolates were identified on the basis of culture characteristics (typical black, convex colonies, with or without light halo), Gram stain reaction, and the results of catalase and tube coagulase tests. Up to 3 characteristic colonies of putative $S$. aureus were purified on tryptone soy agar (Oxoid) with yeast extract and incubated at $35^{\circ} \mathrm{C}$ for 24 to $48 \mathrm{~h}$. All isolates were kept in tryptone soy broth (TSB; Oxoid) with $15 \%$ glycerol, and stored at $-80^{\circ} \mathrm{C}$ for further biofilm assays with PAA.

\section{PAA Treatment of Biofilms on Microtiter Plates}

First, one loopful of each bacterial strain was added to $5 \mathrm{~mL}$ of TSB (Oxoid) and incubated statically at $37^{\circ} \mathrm{C}$ for $24 \mathrm{~h}$. After incubation, the culture broths were diluted until reaching 0.5 on the MacFarland scale $\left(\sim 10^{8}\right.$ cells $\left./ \mathrm{mL}\right)$. Biofilms were formed in a microtiter plate following the method described by Stepanović et al. (2003) with some modifications. Briefly, each bacterial strain was transferred to 3 wells of triplicate aliquots of $200 \mu \mathrm{L}$ of TSB in a 96-well, flat-bottomed plastic microplate and incubated at $37^{\circ} \mathrm{C}$ for $48 \mathrm{~h}$. After incubation, the microplates were washed with sterile PBS (pH 7.2), fixed with methanol (Synth, Diadema,
Brazil), stained using crystal violet $0.1 \%$ (Synth) for $15 \mathrm{~min}$, dried, and resolubilized with $33 \%$ (vol/vol) glacial acetic acid (Synth). The optical density (OD) of each well was measured at $570 \mathrm{~nm}$ using a microtiter plate reader (MultiSkan, Labsystems/Thermo, Waltham, MA). Triplicate negative controls with only sterile TSB were prepared as previously described for bacterial strains, and used as reference for determination of the ability of $S$. aureus and L. monocytogenes strains to produce biofilms. The mean OD value of negative controls $\left(\mathbf{O D}_{\mathrm{NC}}\right)$ was $0.141 \pm 0.02$. Additionally, the strains were classified as weak $\left(\mathrm{OD}_{\mathrm{NC}}<\mathrm{OD}\right.$ $\left.\leq 2 \times \mathrm{OD}_{\mathrm{NC}}\right)$, moderate $\left(2 \times \mathrm{OD}_{\mathrm{NC}}<\mathrm{OD} \leq 4 \times \mathrm{OD}_{\mathrm{NC}}\right)$, or strong ( $\mathrm{OD}>4 \times \mathrm{OD}_{\mathrm{NC}}$ ) biofilm producers, according to Stepanović et al. (2003).

Experiments using BFI were performed in triplicate according to Srey et al. (2014) with some modifications. After a 48-h incubation, the OD value of the total bacteria in the microtiter plate was measured at a wavelength of $600 \mathrm{~nm}$ with a microtiter plate reader (MultiSkan, Labsystems/Thermo). The planktonic cells and medium were removed, and each well was rinsed 3 times with $250 \mu \mathrm{L}$ of PBS to remove the loosely attached cells. Then, $250 \mu \mathrm{L}$ of PAA acid $(0.5 \%$; Dinâmica, Diadema, Brazil) were added for different treatment times $(15,30,60$, and $120 \mathrm{~s})$; instead of disinfectant, PBS was used for treating positive control (well with a bacterial biofilm not subjected to disinfectant challenge) and negative control (well with only TSB). The disinfectant was removed by pipetting immediately after each treatment time, and then $250 \mu \mathrm{L}$ of sodium thiosulfate (Chemco, Hortolandia, Brazil) was introduced into each well, including the control wells, for 5 min to stop the reaction. Finally, the wells were rinsed 3 times with $250 \mu \mathrm{L}$ of PBS. The biofilms were fixed with $250 \mu \mathrm{L}$ of methanol (Synth) for $15 \mathrm{~min}$; after pouring out the methanol, the plates were dried in the inverted position for $30 \mathrm{~min}$. Then, $250 \mu \mathrm{L}$ of crystal violet dye (0.1\%, Synth) was used to stain biofilms and positive and negative control wells for $15 \mathrm{~min}$ and removed by pipetting. The plate was rinsed with distilled water until the washing water was dye free, and air-dried for at least $2 \mathrm{~h}$. The bound dye was resolubilized in $95 \%$ ethanol (Synth) for $30 \mathrm{~min}$ and transferred into a new well plate. The OD of the dye solution was measured at $570 \mathrm{~nm}\left(\mathrm{OD}_{570 \mathrm{~nm}}\right)$.

The biofilm-removing efficacy of the different treatment times using PAA was compared using the BFI calculated with the following formula (Niu and Gilbert, 2004):

$$
\mathrm{BFI}=\frac{\left(\mathrm{OD}_{570 \mathrm{~nm}}-\mathrm{OD}_{\mathrm{C} 570 \mathrm{~mm}}\right)}{\left(\mathrm{OD}_{600 \mathrm{~mm}}-\mathrm{OD}_{\mathrm{C} 600 \mathrm{~mm}}\right)},
$$


where $\mathrm{OD}_{570 \mathrm{~mm}}$ is obtained from the disinfected (treated) or positive control (biofilm treated with PBS) wells after staining; $\mathrm{OD}_{\mathrm{C} 570 \mathrm{~nm}}$ is obtained from negative control wells (TSB wells treated with PBS) after staining; $\mathrm{OD}_{600 \mathrm{~nm}}$ is obtained from the disinfected or positive control wells; and $\mathrm{OD}_{\mathrm{C} 600 \mathrm{~nm}}$ is obtained from negative control wells after 48-h biofilm formation.

\section{PAA Treatment of Biofilms on Stainless Steel}

The production of biofilms on stainless steel was performed according to LIVE/DEAD BacLight (Molecular Probes/Thermo Fisher Scientific, Eugene, OR) manufacturer's protocol, with modifications. A stainless steel coupon $(1.0 \times 1.0 \mathrm{~cm})$ was placed at the bottom of a tube in an inclined position. Next, $2 \mathrm{~mL}$ of each TSB bacterial suspension $\left(\sim 10^{8}\right.$ cells $/ \mathrm{mL}$, or 0.5 on MacFarland scale) was pipetted into each tube and incubated at $35^{\circ} \mathrm{C}$ for $48 \mathrm{~h}$ without stirring. After $24 \mathrm{~h}$, an additional $2 \mathrm{~mL}$ of TSB was added to each tube. After incubation, the stainless steel coupons were removed from each tube with sterile forceps, rinsed with sterile $\mathrm{NaCl}(0.85 \%)$, and placed in a sterile tube. Immediately before treatment, $2 \%$ PAA was diluted to $0.5 \%$ with distilled sterile water. Treatment times chosen were 15 , 30,60 , and $120 \mathrm{~s}$. In each treatment time, $2 \mathrm{~mL}$ of PAA was added, and after each treatment time had elapsed, $6 \mathrm{~mL}$ of sodium thiosulfate was added and left for $5 \mathrm{~min}$ to stop the reaction. After treatment, the tubes were emptied, and the stainless steel coupons were removed from each tube with sterile forceps, placed on a glass slide, and allowed to dry at room temperature.

The viability of surface-bound bacteria was examined using kit L7007 LIVE/DEAD Baclight, which contains Syto-9 and propidium iodide dyes that are usually applied to suspended bacteria. Therefore, $30 \mu \mathrm{L}$ of LIVE/ DEAD Baclight solution was applied directly to the adhered bacteria on stainless steel. After 10 min of incubation, the effects of the PAA treatments on biofilms on stainless steel coupons were examined using an epifluorescence microscope (Nikon Eclipse N1-U 80i with camera software NIS Elements AR 4.13.01 64 bit, 4.0; Nikon, Tokyo, Japan). All treatments were conducted in duplicate, and results were compared using the negative control (biofilm formation without any treatment of each bacterium on stainless steel). Syto-9 is a green fluorescent (maximum emission $498 \mathrm{~nm}$ ) nucleic acid stain that is able to penetrate both healthy and damaged bacterial cells. In contrast, propidium iodide has a maximum emission of $617 \mathrm{~nm}$ and is unable to penetrate healthy bacteria (Karkashan et al., 2015). Therefore, viable cells with intact cell walls allow uptake of only the Syto-9 dye and display green fluorescence, whereas nonviable cells (with damaged cell walls permitting the penetration of propidium iodide) exhibit red fluorescence (Alkawareek et al., 2014).

\section{Statistical Analysis}

All treatments were conducted in independent trials, each having duplicate (stainless steel assays) or triplicate (polystyrene microplates) samples. The BFI values were analyzed by one-way ANOVA using SAS software (SAS Institute, 2002). The means for treatments showing significant differences were compared using the Tukey test. Statistical significance was considered at $P<0.05$.

\section{RESULTS AND DISCUSSION}

Table 1 shows the ability of the $S$. aureus and $L$. monocytogenes strains to produce biofilms in the polystyrene microplate assays. The $4 S$. aureus strains and 1 L. monocytogenes strain were classified as moderate and weak biofilm producers, respectively, according to Stepanović et al. (2003). Biofilm production is recognized as an important virulence factor for bacteria of the genera Staphylococcus and Listeria (Bremer et al., 2006). Hence, formation of biofilms by those pathogens is of major concern for the dairy industry, which may be associated with failure to monitor the operational cleaning standards established for processing foods (Abdallah et al., 2014).

The BFI values for biofilms produced by the 5 bacterial strains in microtiter plates after challenging with PAA $(0.5 \%)$ at different treatment times are presented in Table 2. Peracetic acid removed $(P<0.05)$ adhered cells of $S$. aureus but not $L$. monocytogenes. The $L$. monocytogenes strain used in our experiment was clas-

Table 1. Biofilm formation by Staphylococcus aureus and Listeria monocytogenes strains in the microplate assay

\begin{tabular}{lll}
\hline Strain & \multicolumn{1}{c}{$\mathrm{OD}^{1}$} & Category $^{2}$ \\
\hline Control (tryptone soy broth) & $0.14 \pm 0.02$ & - \\
L. monocytogenes strain & $0.24 \pm 0.01$ & Weak \\
S. aureus strains & $0.40 \pm 0.01$ & Moderate \\
SA1 & $0.36 \pm 0.01$ & Moderate \\
SA2 & $0.37 \pm 0.01$ & Moderate \\
SA3 & $0.29 \pm 0.01$ & Moderate \\
SA4 &
\end{tabular}

${ }^{1} \mathrm{OD}=$ optical density; values are expressed as mean \pm standard deviation of 3 replicates of each strain.

${ }^{2}$ Classified by comparison of each strain's OD with the mean OD value of negative controls $\left(\mathrm{OD}_{\mathrm{NC}}=0.141 \pm 0.02\right)$, according to Stepanović et al. (2003), as follows: weak $\left(\mathrm{OD}_{\mathrm{NC}}<\mathrm{OD} \leq 2 \times \mathrm{OD}_{\mathrm{NC}}\right)$ or moderate $\left(2 \times \mathrm{OD}_{\mathrm{NC}}<\mathrm{OD} \leq 4 \times \mathrm{OD}_{\mathrm{NC}}\right)$ biofilm producers. 
sified as a weak biofilm producer, and the fact that it was not removed by PAA raises concern about the incidence of this pathogen in dairy plants (Välimaa et al., 2015). Importantly, the BFI method allows an estimation of the number of cells that attach to a surface, and therefore an indirect evaluation of the ability of the disinfectant to remove the biofilm (Srey et al., 2014). It does not provide information on the biological state of the cells.

Our results for $S$. aureus biofilms agree with those described by Marques et al. (2007), who found that, compared with hydrogen peroxide and sodium dichloroisocyanurate, PAA was the most efficient in removing adhered cells of $S$. aureus. Those authors obtained 5.26 and 4.5 decimal reductions for adhered cells on stainless steel and glass surfaces, respectively. In the present study, we detected no significant difference $(P>0.05)$ between the BFI for the different treatment times, except for $2 S$. aureus strains (SA2 and SA3). For SA1 and SA4, 15 s of treatment with PAA was sufficient to remove the cells, leading to 40 to $90 \%$ reduction of the bacterial load in the microtiter plates. For SA2 and SA3, lower BFI values $(P<0.05)$ were observed after treatment times of 30 and $60 \mathrm{~s}$, respectively. However, those differences in BFI values were not consistent with the reduction values obtained for SA2 and SA3 at 120 $\mathrm{s}$, which did not differ $(P>0.05)$ from those at other treatment times.

On stainless steel biofilms, all bacterial strains were damaged by PAA (0.5\%) after $15 \mathrm{~s}$, with almost $100 \%$ of cells damaged after $30 \mathrm{~s}$. Figure 1 presents photomicrographs of the LM and SA1 strains after different treatment times with PAA. Results for SA2, SA3, and SA4 were similar to those for SA1. Previous works used crystal violet staining as a colorimetric method to measure biofilm formation by means of the biomass of viable or possibly lysed bacteria adherent to a polystyrene surface (Niu and Gilbert, 2004), as described for the assays with microtiter plate. However, for biofilms prepared on stainless steel, we used the LIVE/DEAD Baclight method to evaluate biofilm formation and the effects of PAA because this staining method does not interfere with cellular viability (Stocks, 2004).

Arias-Moliz et al. (2015) observed that the effect of PAA on Enterococcus faecalis biofilms was lower than that of sodium hypochlorite $(\mathrm{NaClO})$. Those authors postulated that, although PAA was able to diffuse inside the biofilm clusters, its lower antimicrobial effect compared with that of $\mathrm{NaClO}$ could be explained by the resistance of Enterococcus faecalis to PAA oxidative stress. In contrast, the 5 bacterial strains tested in the present study were damaged by PAA after $15 \mathrm{~s}$, with almost $100 \%$ of cells damaged after $30 \mathrm{~s}$ (L. monocytogenes) or $60 \mathrm{~s}$ (S. aureus). After contaminating stainless

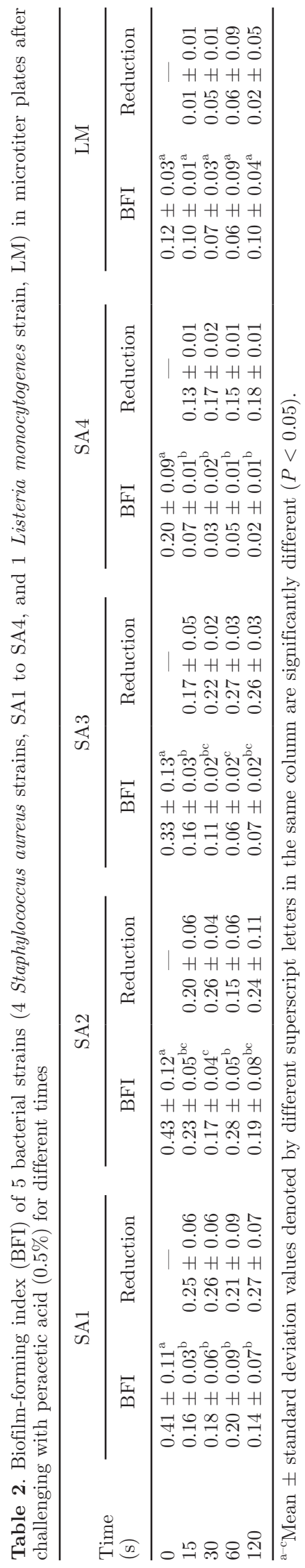

Journal of Dairy Science Vol. 99 No. 3, 2016 

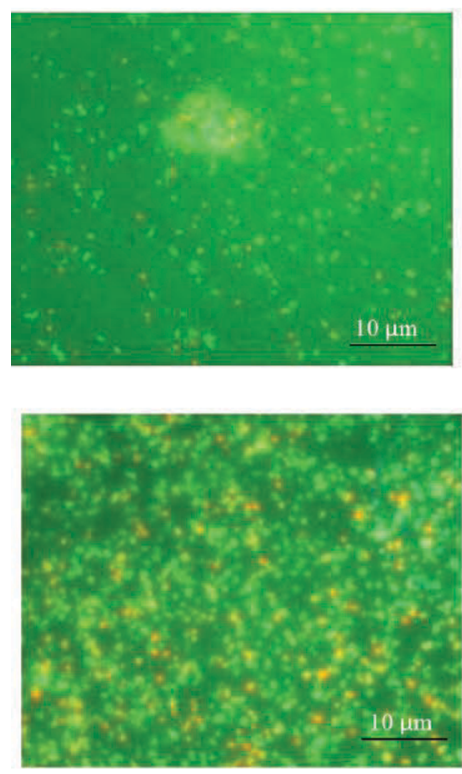

$15 \mathrm{~s}$
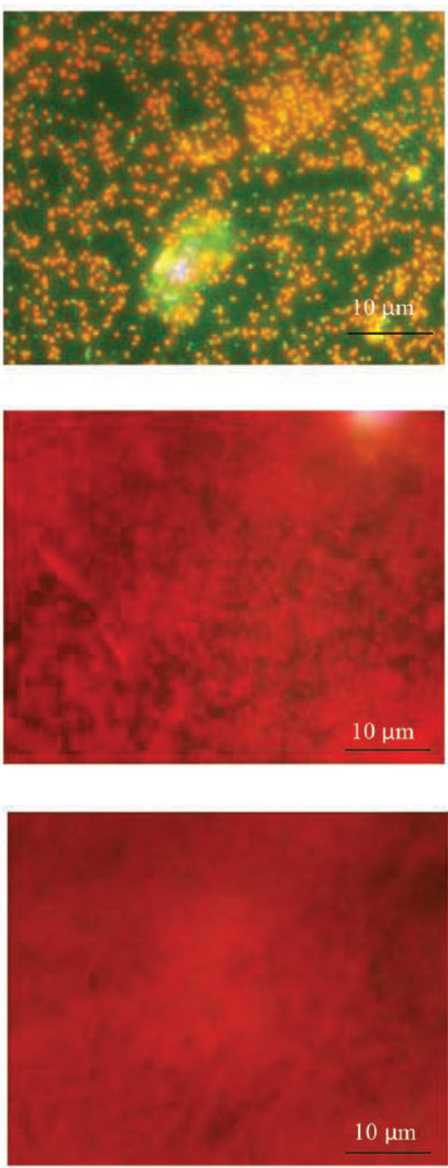

$120 \mathrm{~s}$

$30 \mathrm{~s}$
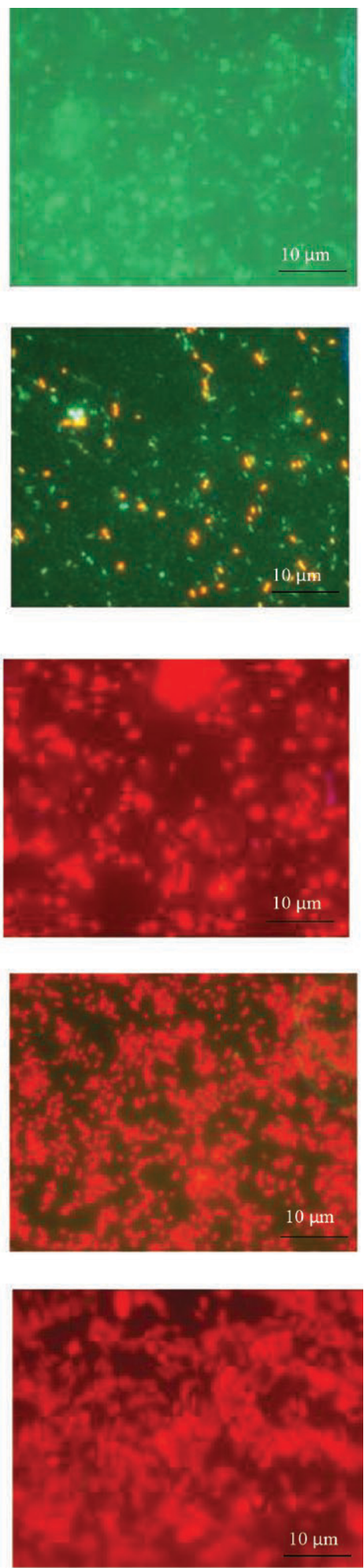

B

Figure 1. Photomicrographs of biofilms formed by Staphylococcus aureus SA1 (A) and Listeria monocytogenes (B) strains stained with LIVE/ DEAD Baclight (Molecular Probes/Thermo Fisher Scientific, Eugene, OR) after treatment with peracetic acid (0.5\%) for 15, 30, 60, and 120 s. Damaged and normal cells are dark (red) and bright (green), respectively. Magnification: 1,000×; bar $=10 \mu \mathrm{m}$. Color version available online. 
steel with S. aureus, Escherichia coli, and Candida albicans, Costa et al. (2015) immersed the specimens in $2 \%$ and $0.25 \%$ PAA for $30 \mathrm{~min}$, and both concentrations significantly eliminated the microorganisms, a result that corroborates the findings of the present study. Moreover, S. aureus and L. monocytogenes are grampositive bacteria with a permeable cell wall (Schäffer and Messner, 2005), which is not considered a barrier to the entrance of antibacterial compounds through the cytoplasmic membrane (Júnior et al., 2014).

The hygiene of the dairy environment is a crucial aspect to be monitored by dairy processors (Cusato et al., 2014). Our findings emphasize the importance of strictly following sanitation procedures, particularly the correct use of PAA for eliminating biofilms formed by $S$. aureus. However, the fact that PAA was not effective in removing adherent cells of $L$. monocytogenes on polystyrene microplates raises concern about its effectiveness against biofilms formed by this pathogen, because the PAA concentration $(0.5 \%)$ used in our study was in the normal range used by dairy processors.

\section{CONCLUSIONS}

Although $0.5 \%$ PAA was able to inactivate $S$. aureus and L. monocytogenes monospecies biofilms on stainless steel, it was able to remove only adherent cells of $S$. aureus on polystyrene microplates. Further studies are necessary to determine the ideal PAA treatment for removing biofilms of $L$. monocytogenes.

\section{ACKNOWLEDGMENTS}

The authors thank the Coordenação de Aperfeiçoamento do Pessoal de Nível Superior (CAPES; Brazil) for the scholarship.

\section{REFERENCES}

Abdallah, M., C. Benoliel, D. Drider, P. Dhulster, and N. E. Chihib. 2014. Biofilm formation and persistence on abiotic surfaces in the context of food and medical environments. Arch. Microbiol. 196:453-472.

Alkawareek, M. Y., S. P. Gorman, W. G. Graham, and B. F. Gilmore. 2014. Eradication of marine biofilms by atmospheric pressure nonthermal plasma: A potential approach to control biofouling? Int. Biodeterior. Biodegradation 86:14-18.

Arias-Moliz, M. T., R. Ordinola-Zapata, P. Baca, M. Ruiz-Linares, E. G. García, M. A. H. Duarte, C. M. Bramante, and C. M. FerrerLuque. 2015. Antimicrobial activity of chlorhexidine, peracetic acid and sodium hypochlorite/etidronate irrigant solutions against Enterococcus faecalis biofilms. Int. Endod. J. 48:1188-1193.

Barancelli, G. V., T. M. Camargo, C. M. F. Reis, E. Porto, E. Hoffer, and C. A. F. Oliveira. 2011. Incidence of Listeria monocytogenes in cheese manufacturing plants from the northeast region of São Paulo, Brazil. J. Food Prot. 74:816-819.
Belessi, C. E., A. S. Gounadaki, A. N. Psomas, and P. N. Skandamis. 2011. Efficiency of different sanitation methods on Listeria monocytogenes biofilms formed under various environmental conditions. Int. J. Food Microbiol. 145:S46-S52.

Bremer, P. J., S. Fillery, and A. J. Mcquillan. 2006. Laboratory scale clean-in-place (CIP) studies on the effectiveness of different caustic and acid wash steps on the removal of dairy biofilms. Int. J. Food Microbiol. 106:254-262.

Cappitelli, F., A. Polo, and F. Villa. 2014. Biofilm formation in food processing environments is still poorly understood and controlled. Food Eng. Rev. 6:29-42.

Cos, P., K. Toté, T. Horemans, and L. Maes. 2010. Biofilms: An extra hurdle for effective antimicrobial therapy. Curr. Pharm. Des. 16:2279-2295.

Costa, S. A., O. F. Paula, C. R. Silva, M. V. Leão, and S. S. Santos. 2015. Stability of antimicrobial activity of peracetic acid solutions used in the final disinfection process. Braz. Oral Res. 29:1-6.

Cusato, S., A. S. Sant'Ana, C. H. Corassin, A. G. Cruz, J. A. F. Faria, and C. A. F. Oliveira. 2014. Assessing the costs involved in the implementation of GMP and HACCP in a small dairy factory. Qual. Assur. Safety Crops Foods 6:135-139.

Falsanisi, D., R. Gehr, D. Santoro, A. Dell'Erba, M. Notarnicola, and L. Liberti. 2006. Kinetics of PAA demand and its implications on disinfection of wastewaters. Water Qual. Res. J. Canada 41:398 409.

Júnior, A. C. S., A. P. S. Salimena, M. G. Cardoso, E. Alves, and R. H. Piccoli. 2014. Action of sanitizers on Staphylococcus aureus biofilm on stainless steel and polypropylene surface. Afr. J. Microbiol. Res. 8:3347-3353.

Karkashan, A., B. Khallaf, J. Morrisa, N. Thurbon, D. Rouch, S. R. Smith, and M. Deighton. 2015. Comparison of methodologies for enumerating and detecting the viability of Ascaris eggs in sewage sludge by standard incubation-microscopy, the BacLight Live/ Dead viability assay and other vital dyes. Water Res. 68:533-544.

Lee, S. H., C. H. Camargo, J. L. Gonçalves, A. G. Cruz, B. T. Sartori, M. B. Machado, and C. A. F. Oliveira. 2012. Characterization of Staphylococcus aureus isolates in milk and the milking environment from small-scale dairy farms of São Paulo, Brazil, using pulsedfield gel electrophoresis. J. Dairy Sci. 95:7377-7383.

Marques, S. C., J. G. O. S. Rezende, L. A. F. Alves, B. C. Silva, E. Alves, L. R. Abreu, and R. H. Piccoli. 2007. Formation of biofilms by Staphylococcus aureus on stainless steel and glass surfaces and its resistance to some selected chemical sanitizers. Braz. J. Microbiol. 38:538-543.

Martins, E. A., and P. M. L. Germano. 2011. Listeria monocytogenes in ready-to-eat, sliced, cooked ham and salami products, marketed in the city of São Paulo, Brazil: Occurrence, quantification, and serotyping. Food Contr. 22:297-302.

Niu, C., and E. S. Gilbert. 2004. Colorimetric method for identifying plant essential oil components that affect biofilm formation and structure. Appl. Environ. Microbiol. 70:6951-6956.

Ölmez, H., and U. Kretzschmar. 2009. Potential alternative disinfection methods for organic fresh-cut industry for minimizing water consumption and environmental impact. Food Sci. Technol. (Campinas.) 42:686-693.

Römling, U., and C. Balsalobre. 2012. Biofilm infections, their resilience to therapy and innovative treatment strategies. J. Intern. Med. 272:541-561.

SAS Institute. 2002. User's Guide for SAS software. 9th ed. SAS Institute Inc., Cary, NY.

Sasidharan, S., B. Prema, and L. L. Yoga. 2011. Antimicrobial drug resistance of Staphylococcus aureus in dairy products. Asian Pac. J. Trop. Biomed. 1:130-132.

Schäffer, C., and P. Messner. 2005. The structure of secondary cell wall polymers: how gram-positive bacteria stick their cell walls together. Microbiology 151:643-651.

Simões, M., L. C. Simões, and M. J. Vieira. 2010. A review of current and emergent biofilm control strategies. Food Sci. Technol. (Campinas.) 43:573-583. 
Souza, E. L., Q. G. S. Meira, I. M. Barbosa, A. J. A. Athayde, M. L. Conceição, and J. P. S. Júnior. 2014. Biofilm formation by Staphylococcus aureus from food contact surfaces in a meat-based broth and sensitivity to sanitizers. Braz. J. Microbiol. 45:67-75.

Srey, S., S. Y. Park, I. K. Jahid, S. R. Oh, N. Han, C. Y. Zhang, S. H. Kim, J. I. Cho, and S. D. Ha. 2014. Evaluation of the removal and destruction effect of a chlorine and thiamine dilaurylsulfate combined treatment on L. monocytogenes biofilm. Foodborne Pathog. Dis. 11:658-663.

Stepanović, S., I. Ćirković, V. Mijač, and M. Švabić-Vlahović. 2003. Influence of the incubation temperature, atmosphere and dynamic conditions on biofilm formation by Salmonella spp. Food Microbiol. 20:339-343.

Stocks, S. M. 2004. Mechanism and use of the commercially available viability stain, BacLight. Cytometry 61:189-195

Surdeau, N., D. Laurent-Maquin, S. Bouthors, and M. P. Gellé. 2006. Sensitivity of bacterial biofilms and planktonic cells to a new antimicrobial agent, Oxsil 320N. J. Hosp. Infect. 62:487-493.

Välimaa, A. L., A. Anu Tilsala-Timisjärvi, and E. Virtanen. 2015. Rapid detection and identification methods for Listeria monocytogenes in the food chain-A review. Food Contr. 55:103-114. 